\title{
Dünyadaki Önemli Keman Ekolleri ve Türkiye’de Uygulanan Ekoller
}

$$
\text { Özlem Akın-Şişman }{ }^{1}
$$

${ }^{I}$ GSEB Müzik Eğitimi Anabilim Dall, Eğitim Fakültesi, Pamukkale Üniversitesi, Denizli, Türkiye

Sorumlu Yazar: Özlem Akın Şişman, oakin@pau.edu.tr

Makale Türü: Araştırma Makalesi

Bilgilendirme: Makale daha önce MÜZED Uluslararası 2. İpekyolu Müzik Konferansı'nda bildiri olarak sunulmuştur.

Kaynak Gösterimi: Akın-Şişman, Ö. (2018). Dünyadaki önemli keman ekolleri ve Türkiye'de uygulanan ekoller. Eğitimde Kuram ve Uygulama, 14(4), 361-375. doi: 10.17244/eku.420858

\section{Leading Violin Schools Around the World and Schools Applied in Turkey}

$$
\text { Özlem Akın-Şişman }{ }^{1}
$$

${ }^{1}$ Department of Music Education, Faculty of Education, Pamukkale University, Denizli, Turkey

Corresponding Author: Özlem Akın Şişman, oakin@pau.edu.tr

Article Type: Research Article

Acknowledgement: This article was presented in the 2nd International SilkRoad Music Conference of MÜZED.

To Cite This Article: Akın-Şişman, Ö. (2018). Dünyadaki önemli keman ekolleri ve Türkiye’de uygulanan ekoller, Eğitimde Kuram ve Uygulama, 14(4), 361-375. doi: 10.17244/eku.420858 


\title{
Dünyadaki Önemli Keman Ekolleri ve Türkiye'de Uygulanan Ekoller
}

\author{
Özlem Akın-Şişman ${ }^{1}$ \\ ${ }^{1}$ GSEB Müzik Eğitimi Anabilim Dalı, Eğitim Fakültesi, Pamukkale Üniversitesi, Denizli, Türkiye \\ ORCID: http://orcid.org/0000-0003-2115-8416
}

\begin{abstract}
$\ddot{\mathbf{O z z}}$
Milyonlarca yıl içerisinde gelişimi ve evrimi tamamlanan dünyanın ve dolayısıyla insanoğlunun bilişsel, duyuşsal ve psiko-motor gelişiminin oluşmasında sanatın çok farklı ve kendine özgü bir yeri vardır. İnsanın yaşamında çok önemli bir yere sahip olan sanatın en önemli dallarından biri kuşkusuz müzik sanatıdır. Bu çalışmada, müzik sanatının içerisinde kendine yer edinmiş olan kemanın tarihçesine göz gezdirilmiş, Avrupa'da ve dünyada öne çıkmış önemli keman okulları araştırılmıştır. Türkiye'deki durumu belirlemek üzere uzman görüşlerine başvurulmuş, Dokuz Eylül Üniversitesi ve Anadolu Üniversitesi Devlet Konservatuvarları, Gazi Üniversitesi, Niğde Üniversitesi ve Mehmet Akif Ersoy Üniversitesi Güzel Sanatlar Eğitimi Bölümü Müzik Eğitimi Anabilim Dalları keman öğretim elemanları ile görüşme yapılmıştır. Uzmanlara dört açık uçlu soru sorulmuş, bulgular 1şığında Türkiye'deki duruma ilişkin saptamalarda bulunularak, konuyla ilgili sonuç ve öneriler sunulmuştur.
\end{abstract}

\section{Makale Bilgisi \\ Anahtar Kelimeler: Keman, Keman eğitiminde ekoller, Kemanın evrimi, Türk keman ekolü}

Makale Geçmişi:

Geliş: 03 Mayıs 2018

Düzeltme: 25 Eylül 2018

Kabul: 05 Ekim 2018

Makale Türü: Araștırma

Makalesi

\section{Leading Violin Schools Around the World and Schools Applied in Turkey}

\begin{abstract}
Art has a very different and unique place specific to itself in the cognitive, affective and psycho-motor development of the world, and therefore human beings, whose evolution was completed in millions of years. One of the most important branches of art, which has a very significant place in human life, is undoubtedly the art of music. In this study, the history of the violin, which has taken its place in music, is examined and important violin schools which have come to prominence in Europe and in the world are investigated. Expert opinions were used to determine the situation in Turkey, interviews were held with faculty members of Dokuz Eylül University and Anadolu University State Conservatoires, and with instructors in the Music Education Department of Fine Arts Education in Gazi University, Niğde University and Mehmet Akif Ersoy University. The experts were asked four open-ended questions and the situation in Turkey was explained while conclusions and suggestions related to the topic were presented in the light of the findings.
\end{abstract}

\section{Article Info}

Keywords: Evolution of violin, Schools in violin education, Turkish violin school, Violin

Article History:

Received: 03 May 2018

Revised: 25 September 2018

Accepted: 05 October 2018

Article Type: Research Article 


\section{Giriş}

İnsanoğlu, varoluşundan bu yana kendini ifade etmek için çeşitli yollara başvurmuştur. Bunlardan ilki tahmin edileceği gibi kendi sesi ve vücudu olmuştur. Kendi sesini keşfeden insan zamanla konuşarak birbiri ile iletişime geçmiştir. Kendi sesini ve vücudunu kullanan insanoğlu, zamanla doğada bulunan malzemeleri de kullanarak farklı sesleri keşfetmiş ve bunu müziğe çevirmesini bilmiştir. Bunların yanısıra kendini ifade etmek ve arasındaki iletişimi sağlayabilmek için mağara duvarlarına resimler de çizerek ilk sanat eserlerini vermiştir.

Müzik enstrümanları, insanlık tarihinin evrensel bileşenlerinden biridir. Müzik enstrümanlarının önemli bir kısmı antik mağaralardan, mezar ve tapınaklardan çıkarılmıştır. Bilim insanları çıkarılan bu müzik enstrümanlarını yeniden inşa edebilmiş, ve bazen birebir ölçeklerini dahi belirleyebilmişlerdir. Ancak hiçbiri de bu enstrümanlarla yapılmış olan müziği tekrar yaratamamışlardır (Miller, 1973, s. 8).

İnsanoğlunun alet yapmaya başlamasıyla ilk düşünce ve kültür üretimi başlar. Alt, orta ve üst paleolitik dönemlerden oluşan Paleolitik Çağ, Neolitik Devre hazırlık niteliğindedir. Üst paleolitik dönemde yapılan aletler genel olarak av amaciyla yapılıyordu. Kendisini korumak ya da avlanmak amaciyla yaptığı aletlerin yanısira insanoğlu, doğal olarak müzik aletleri de yapmıştır. Curt Sachs'ın teorilerinden yola çıkıldığında, çalgıların da basitten karmaşığa doğru yapıldığını, bu şekilde meydana getirildiklerini görüyoruz. Ayrıca Sachs, müziğin birincil kökeninin, zaman akışını tempo, vuruş ve ölçülerle temin eden ritim olması nedeniyle ilk etapta vurmalı çalgıların üretildiğini söylemektedir (Sachs, 2006, ss. 25-26, aktaran Dönmez, 2015, ss. 59-60).

Binlerce yıl süren gelişim evresinde insanoğlu bilim ve teknikte olduğu kadar sanatta da büyük ilerleme kaydetmiştir. Müzik alanında da ilkçağlardan bu yana çalgıların, nota yazım biçimlerinin, besteleme teknik ve formlarının sürekli gelişim ve değişim gösterdiği görülmektedir. Bununla bağlantılı olarak insanoğlunun yarattığ 1 çalgılar da zaman içerisinde değişim ve gelişime uğramış, çağın gerektirdiği şekilde evrimleşmişlerdir.

\section{Yaylı Çalgıların Kökeni ve Kemanın Evrimi}

Hornbostel ve Sachs (1914), enstrümanları yayl1, üflemeli ve vurmalı olarak üç ana kategoriye ayırmışlardır (Baines \& Wachsmann, 1961, s. 5). Yaylı sazlar ailesinden olan kemanın atalarını gözden geçirecek olursak, organologlar, yaylı çalgıların öncelikle telli olarak kullanıldıklarını belirtmekle birlikte, telli çalgıların kökeninin ise İ.Ö. 3000'e kadar uzandığını ve eski Mısır' da ortaya çıktığını dile getirmektedirler. Yayla çalınan telli çalgıların kökeninin ise büyük bir olasılıkla Orta Asya'ya, 9. Yüzyıla kadar giden bir tarihinin olduğu düşünülür. Avrupa'da yayla çalınan telli çalgılar ilk kez 10. yy'da görülmüştür (https://vsl.co.at/en/Violin/History, erişim tarihi: 10.02.2016).

Kemanın bugünkü şeklini alması Rönesans'ın son dönemlerine rastlamaktadır. İncil'de ve eski mezmurda parmakla çalınan telli çalgıların olduğundan da bahsedilmekte olup yayın çok daha sonra ortaya çıktığı bilinmektedir. Bachmann yaptığı araştırmalarla, 10. ve 11. yüzyıllarda Bizans ve İslam tarihindeki resimlere ve o dönemdeki yazmalara dayanarak, yayın tarihinin bu döneme kadar gittiğini bulmuştur. Yay Avrupa'ya, doğudan İslami fetihlerle yayılmıştır. 10.yy. sonuna kadar Arap ve Bizans'ın sınırları içinde kalmış olan "yay" 11. yüzyılda İspanya'dan Avrupa'ya yayılmıştır (Nelson, 2003, ss. 1-2).

Yaylı çalgılardan şüphesiz ki en çok bilineni kemandır. Kemanın evrimi konusunda çok fazla görüş olmasıyla birlikte, "keman gelişim sürecinde birkaç telli çalgının karmaşık etkileşimi sonucu oluşmuştur. Atasının gitara benzer fidel çalgısı olduğu düşünülse de kemanın evrimi Batı Avrupa'da bilinen rebec ve lira da braccio çalgısıyla ilerlemiştir" (Struve, 1959, s. 211, aktaran Kerimov, 2015, s. 248).

20. Yüzyılda yapılan araştırmalarda kemanın gelişiminin Rebec-Fidel-Lira da braccio-Keman şeklinde geliştiğine değinilmiştir (Kerimov, 2015, s. 248). Rebec çalgısının kökeninin ise Arap çalgısı rebapa dayandığı bilinmektedir. Dokuzuncu yüzyıla kadar geçmişi olduğu yazılı kaynaklardan bilinen rebap çalgısını, 14. yy'da İbn-i Haldun, Mukaddime adlı eserinde anlatmış, dize koyularak, yayla çalınan rebap çalgısından bahsetmiştir. Bundan önce, rebap'ın 11. yy.'da haçlı seferleri esnasında Kuzey Afrika'dan Avrupa'ya gittiği tahmin edilmektedir. 


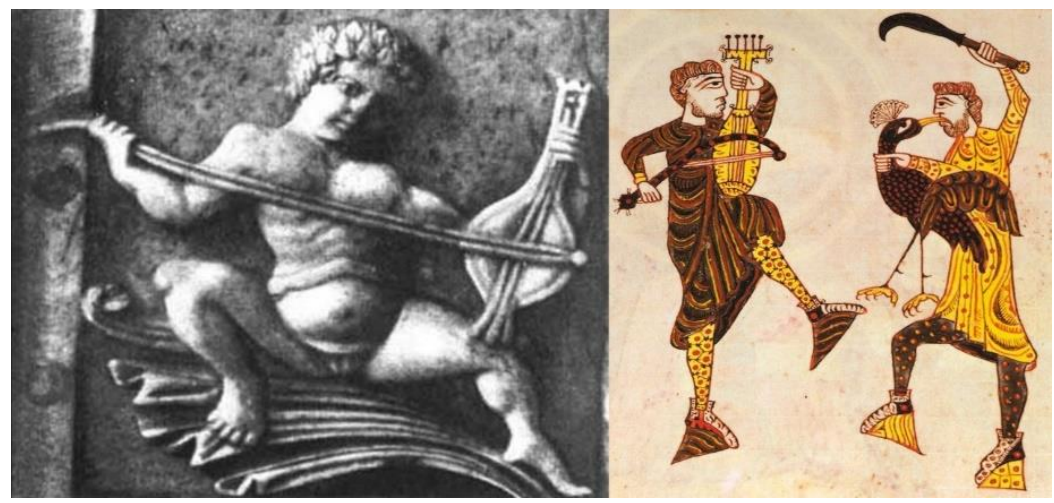

Resim 1. Solda: Bizans rebap1 İ.S. 1000, Museo Nazionale, Florence. Sağda: İspanya antifonu İ.S. 1109 British Library (http://earlymusicmuse.com/rebec/ erişim tarihi: 31.3.2016)

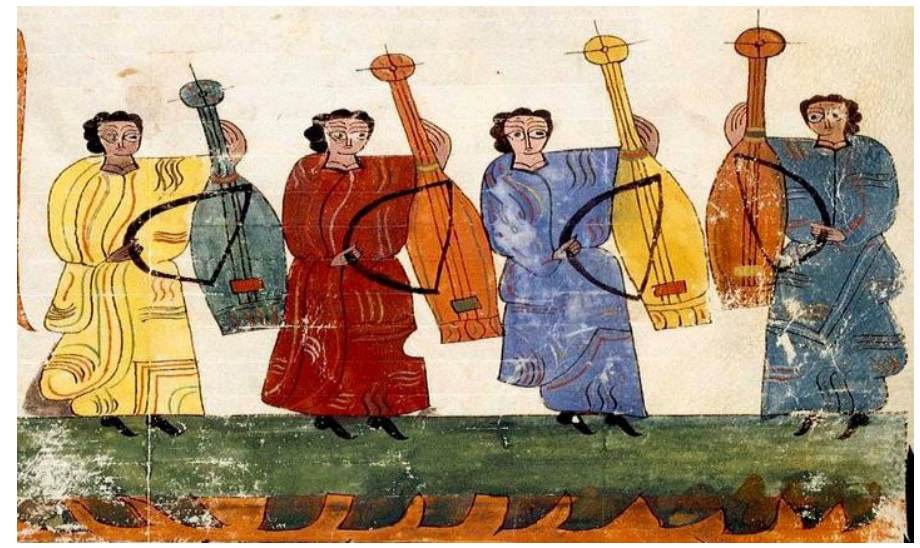

Resim 2. İ.S. 950, Yaylı Çalgılar, Serafin Estebanez Calderon Kütüphanesi: San Millan de la Cogolla, İspanya (http://davidofsantabarbara.com/Galleries/Art/Gallery\%20-\%20Art\%20\%20950\%20AD\%20\%20Bowed\%20Strings.htm erişim tarihi: 2.5.2016).

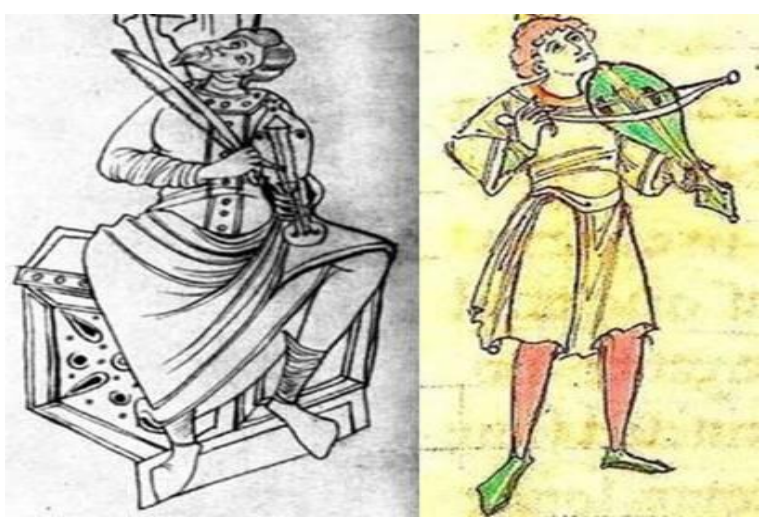

Resim 3. Solda: Avrupa rebek çalgısı, İ.S. 1050 Katalan Mezmuru'ndan. Sağda: 12. yy'ın ilk çeyreğinde rebek çalgısı (http://earlymusicmuse.com/rebec/ erişim tarihi: 31.3.2016).

Resimlerde görüldüğü gibi dize dayalı olarak çalınan rebap çalgısı, Avrupa'da değişime uğramış ve omuza dayanarak çalınmaya başlanmıştır. 11. yüzyılla 13. Yüzyıllarda şarkı söyleyip şiir okuyan gezgin ozanlar [minstrels (İlyasoğlu, 2009, s. 25)] tüm Avrupa'yı dolaşarak kemanın atası olan rebek' in yayılmasını sağlamışlardır. "Kemanın oluşumu sürecindeki bir diğer etkin çalgı olan Fidel yaklaşık 13. yüzyılda Avrupa'da ortaya çıkmıştır. Ortaçağ Avrupası'nda dönemin en yaygın çalgısı, modern kemanın ataları arasında önemli bir yer tutmaktadır. Aynı zamanda Vielle adıyla anılan bu çalgı Rönesans Dönemine ait viol'ların ön biçimi ve bugünkü viyolanın atası sayılır (Chisholm, 1910, s.320, aktaran: Kerimov, 2015, s. 250). 


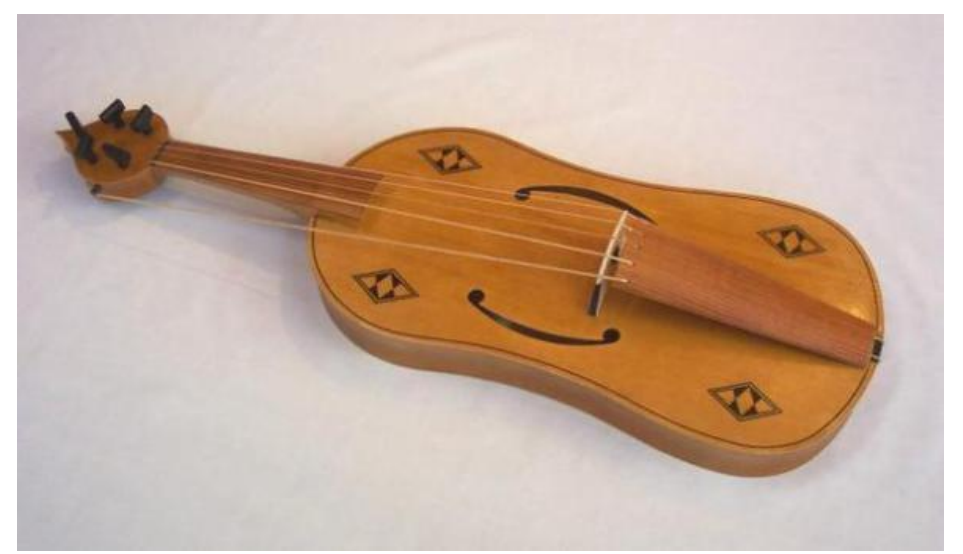

Resim4. Fidel (vielle). (https://mrcaseyhistory.com/2014/03/12/study-tunes-unit-five-music-of-the-vielle/ erişim: 31.3.2016).

Bizans lirası, diğer bir deyişle fidel, vielle ya da viyola Ortaçağ Avrupası'nın ana çalgısı olmuştur. Avrupa fidelinin 10. ve 11. yüzyıllar arasındaki resimlemelerinde 1, 3, 4 ya da 5 telli olduğu görülmektedir. Batıda fidelin akord düzenini sadece 1250 yılında Paris’te yaşayan Hieronimus de Moravia dile getirmiştir. Buna göre çalgının akordu "d G g d' d', d G g d' g' ya da G c g d" şeklinde yapılıyordu. Başlarda çello gibi dikey olarak tutularak çalınan fidel, Avrupa'ya geldiğinde hemen hiç dikey olarak çalınmamış, tutuş pozisyonu aynı modern kemanda olduğu gibi omuza yaslanmıştır (Sachs, 2006, ss. 276- 277).

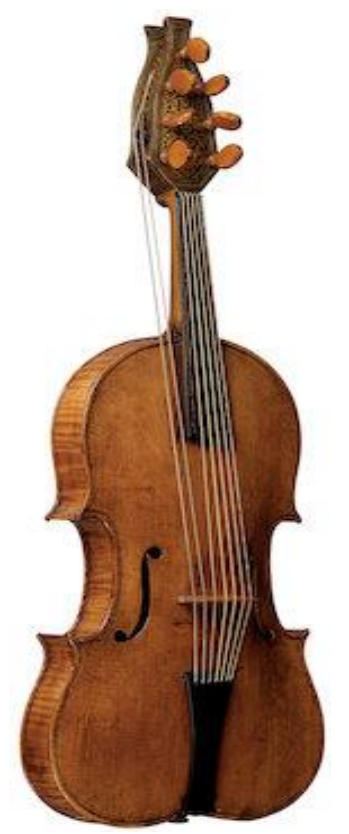

Resim5. Lira Da Braccio 1525, Giovanni Maria da Brescia,

(http://www.ashmoleanprints.com/image/1056136/giovanni-maria-da-brescia-lira-da-braccio-c-1525, Ashmolean

Museum of Art and Archaeology University of Oxford, erişim:5.4.2016).

Lira ailesi, 15. ve 17. Yüzyıllar arasında popüler olarak kullanılan fidel soyundan gelen kemanla aynı forma sahip çalgılardır. Lira da braccio'nun, 5 teli olup, 2 de monoton eşlik teli bulunmakta idi. Soprano ses rengine sahip olan lira da braccio'nun $f$ ya da $c$ delikleri bulunmakla birlikte, üç dört telin aynı anda çalınmasını sağlayacak şekilde eşiği düz yapılmıştır. Akordu ise bugünkü kemanın akordu gibi yapılırdı (Sevsay, 2013, s. 70).

Rönesans ile birlikte tüm çalgılar değişim ve gelişim yaşamışlardır. Kemanla ilgili ilk ayrıntılı betimleme Philibert Jambe de Fer's Epitome Musical (Lyons, 1556) eserinde görülmekle birlikte, çalg1, çeyrek yüzyıl kadar önce Kuzey İtalya'da gelişmiştir. İkonolojik kanıtlar da geç 15. Yüzyıl İtalyan fresklerinde keman benzeri üç telli çalgıları destekler niteliktedir. Özellikle Gaudenzio Ferrari'nin freskleri keman ailesinin resimlenmesi açısından önemlidir (Stowell, 2004, s. 28). 


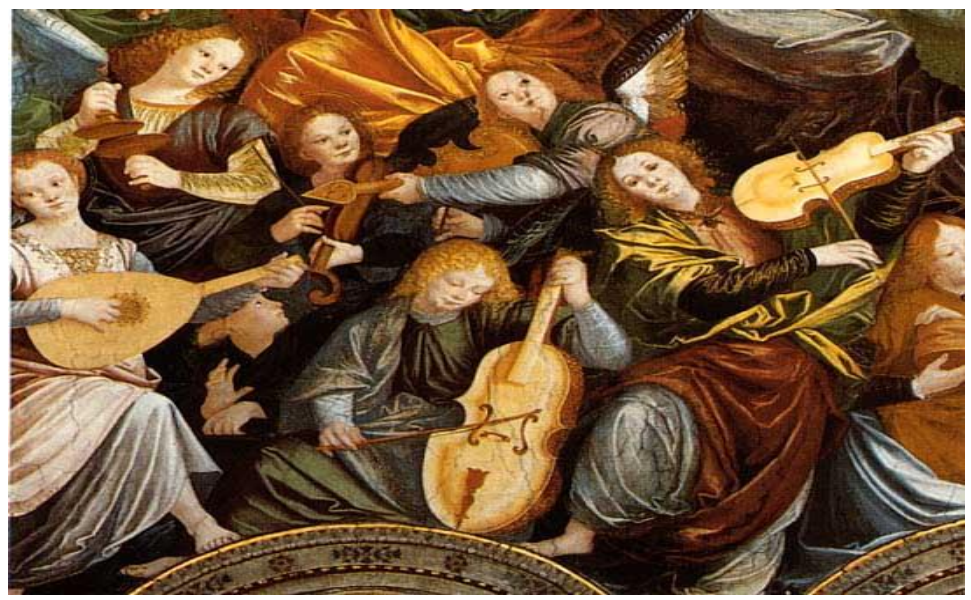
Resim6.
Keman
ailesi
(1535),
Gaudenzio
Ferrari,
Saronno
Katedrali, İtalya. (http://www.orpheon.org/OldSite/Seiten/education/OldestViolin.htm Erişim tarihi: 5.04.2016)

XVI. yüzyılda evrim süreci içinde birçok melez türüne rastlanabilen lira da braccio’nun üç telli bir versiyonu olan lira viola yeni yeni ortaya çıkacak olan kemanın habercisi gibidir. XVI. yüzyılın başında ismi bilinmeyen bir mucit, Rönesans kemanının potansiyelini, rebeklerin akort etmedeki avantajlarını ve lira da braccio'nun tınıyı (sonorite) çok olumlu yönde etkileyen can direği unsurunu aynı enstrüman bünyesinde toplama düşüncesini geliştirmiştir. Beşli aralıkların kulak tarafından daha kolay algılanması, daha az telle sol el tekniğinin daha etkin kullanılabilmesi burada etkin rol oynamış olabilir (Erdal, 2010, s. 7).

Az önce bahsi geçen rebap, rebec, fidel, lira da braccio ve lira viyola çalgılarının tümünün evrimleşip gelişerek bugünkü keman formunu oluşturduğu görülmektedir. Son zamanlardaki yapılan araştırmalara göre kemanın, 15. yy. sonu ya da 16. yy. başlarında Kuzey İtalya'da büyük ihtimalle Brescia ve Cremona yakınlarında yapılmış bir çalgı olduğu düşünülmektedir. Birkaç yıl içerisinde buradan tüm Avrupa'ya yayılmış, kısa sürede geçerli ve tercih edilen bir çalgı olarak kabul görmüştür. Keskin tonu, esnek ve geniş ses perdesi ile eğlence mekanlarının, kilise, tiyatro ve sarayların toplantı yerlerinin gözde çalgısı olmuştur (Zaslaw, 1990, s. 515). "Keman ve yaylı çalgılar ailesinin diğer üyeleri evrimlerini tamamladıktan sonra özellikle keman; luthierler tarafindan en çok üretilen enstrüman olmuştur. Tarihte bilinen en büyük keman yapımcısı luthierler arasında İtalya'dan Gasparo da Salo, Andrea Amati ve oğulları, Francesco Rugeri, Antonio Stradivari ve oğulları, Giuseppe Guarneri ve oğlu Giuseppe 'del Gesu' Guarneri, Carlo Bergonzi, Giovanni Paolo Maggini; Almanya'dan Jacob Stainer, Fransa'dan Nicolas Lupot, Francois Pique, Jean Baptiste Vuillaume sayılabilir. Sonuç olarak denebilir ki; XVI. yüzyılda temel yapısal özelliklerine kavuşmuş olan keman başta İtalyan ustalar olmak üzere luthierlerin ve luthierlik mesleğinin gelişimiyle paralel olarak ilerleyip mükemmelleşmiş, 1710 yılında da günümüz modern kemanı, son değişiklikleri yapılmış olarak müzik evreninde yerini almıştır” (Erdal, 2010, s. 9). 


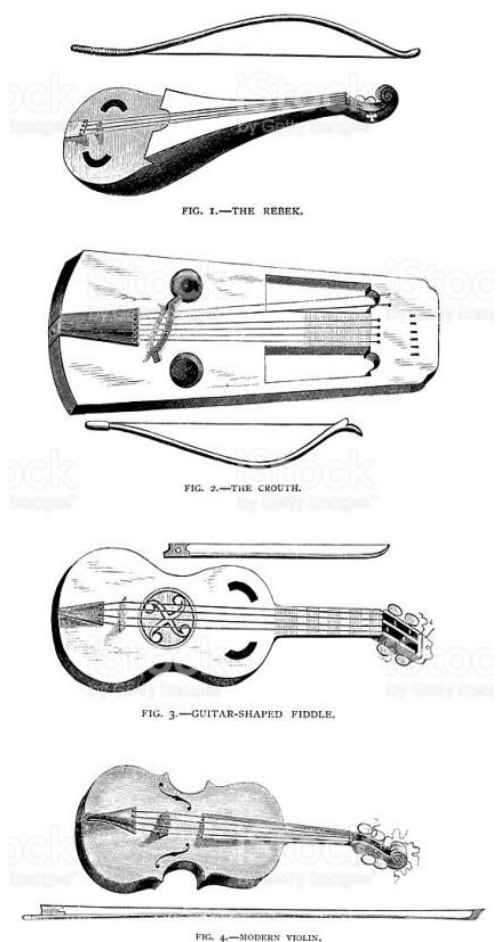

Resim8. Kemanın evrimi (http://www.istockphoto.com/tr/vekt\%C3\%B6r/evolution-of-the-violin-victorianillustration-gm466419723-20301530 Erişim tarihi: 26.10.2017)

Problem: Dünyada kullanılan keman eğitimi ekolleri hangileridir ve Türkiye'de kullanılan ekoller ile Türk Keman Okulu'na ilişkin uzman görüşleri nelerdir?

1. Dünyada kullanılagelen keman eğitimi ekolleri hangileridir?

2. Türkiye'de keman eğitiminde kullanılan ekoller hangileridir?

3. Türk keman ekolüne ilişkin uzman görüşleri nelerdir?

\section{Amaç ve Önem:}

Bu çalışma, 17. yy.'dan itibaren keman edebiyatında ortaya çıkan keman eğitimi ekollerini araştırarak, bu konudaki alanyazına katkıda bulunması ve Türkiye'de kullanılan ekolleri belirlemek amacıyla yapılmıştır. Türkiye'de keman eğitimi ekolleri ile ilgili olarak yapılan çalışmaların sınırlı sayıda olması dikkati çekmektedir. Bu bağlamda araştırmanın, bu konuda bilgi edinmek isteyen ve araştırmalarını bu doğrultuda gerçekleştirmek isteyen kemancılara yol göstermesi ve bilinçlendirmesi açısından önemli olduğu düşünülmektedir.

\section{Yöntem}

Araştırma, betimsel bir çalışma olup ilk aşamada kaynak tarama yöntemi ile bilgiler bir araya getirilmiştir. Araştırmanın nitel kısmında ise deneyimli keman sanatçı eğitimcileri ve uzman keman eğitimcileri ile görüşme yapılarak konuya ilişkin görüş ve önerileri çalışmaya eklenmiştir.

Nitel araştırmalarda, bir dersin nasıl öğretildiği, bu ders için nasıl hazırlanıldığı, öğrencilerin neler yaptıkları, ne tür etkinliklerin işe koşulduğu, öğrenme sürecini olumlu ve olumsuz yönde etkileyen faktörlerin neler olduğu araştırılır (Büyüköztürk, Çakmak, Akgün, Karadeniz, Demirel , 2016, s. 244).

"Nitel bir çalışmada detaylı alan kayıtlarının alınması, araştırma ekibi tarafından doğru ve kapsamlı bilgi sağlaması, doğruluk için alan notlarının katılımcılar tarafından incelenmesi, ses ve görüntü kayıtlarının tutulması, resimlerin çekilmesi, katılımcılardan alıntıların yapılması ve alıntıların ekleme yapılmadan olduğu gibi verilmesi güvenirliği artırmaktadır" (Büyüköztürk vd., 2016, s. 256). Buradan hareketle bu araştırmada uzmanlarla yapılan yüzyüze görüşmelerde hem kısa notlar alınmış hem de ses kaydı yapılarak bilgilerin kaybolmaması sağlanmış, araştırmanın güvenirliği açısından tüm veriler açık ve net bir şekilde gruplandırılarak bulgular ve yorum kısmında sunulmuştur. Ayrıca uzmanların cümleleri olabildiğince değiştirilmeden çalışmaya yansıtılmıştır. 


\section{Veri Toplama Araçları}

Araştırmaya ilişkin veriler toplanırken, araştırmacı tarafından oluşturulan yarı yapılandırılmış görüşme formu kullanılmıştır. Konuya ilişkin sorulması gereken sorular liste halinde sıralanmış ve keman eğitimi alanında uzman üç öğretim elemanından görüş alınmıştır. Alınan görüşler doğrultusunda dört sorudan oluşan yarı yapılandırılmış görüşme formu hazırlanmıştır.

\section{Çalışma Grubu}

Çalışmanın nitel kısmı örneklemini üç müzik eğitimi bölümü öğretim üyesi ve iki devlet konservatuvarı öğretim üyesi olmak üzere toplam beş keman eğitimcisi oluşturmaktadır. Katılımcıların çalıştığı kurumlar Gazi Üniversitesi, Niğde Üniversitesi, Mehmet Akif Ersoy Üniversitesi Müzik Eğitimi Bölümleri, Dokuz Eylül Üniversitesi ve Anadolu Üniversitesi Devlet Konservatuvarlarıdır. Çalışma grubu random sistemle seçilmiş öğretim elemanlarından oluşmaktadır.

\section{Sanatın İçinde Ekol Kavramı}

\section{Bulgular ve Yorum}

Öncelikle "ekol" kelimesini açıklamak faydalı olacaktır. Fransızca ecole kelimesinden dilimize geçmiş olan kavram Türk Dil Kurumu Sözlüğü’nde "bir bilim ve sanat kolunda ayrı nitelik ve özellikleri bulunan yöntem veya akım, okul” (Türk Dil Kurumu [TDK], 2005, s. 612) şeklinde tanımlanmıştır. Bu tanımdan yola çıkarak, bir grup sanatçının kendilerine özgü oluşturdukları farklı tarz ve biçimlerde eserler vermeleri bir akım oluşturmakta ve aynı zamanda okul olarak da adlandırılmaktadır. Ülkelerin kendilerine özgü oluşturdukları ekolleri olabileceği gibi, aynı görüş ve düşünceleri paylaşan, ortak paydada birleşen düşünürler, benzer üslupta eserler veren edebiyatçılar, ressamlar ve müzisyenler de bir ekolü oluşturabilirler.

Plastik sanatlarda daha çok karşımıza çıkan ekol kavramı müzik sanatında da kendini göstermektedir. Özellikle konunun ilgili olması açısından keman eğitiminde İtalya, Fransa, Alman, Fransa-Belçika ve Rus ekollerinden bahsetmek mümkündür. "Önceleri sadece usta-çırak ilişkisi ile bilgi aktarma geleneği, sonradan bir sistem ve anlayış çerçevesinde devam ettirilmiş; bu sayede bir düzen dahilinde gerçekleşen usta-çırak ilişkisi "Ulusal Okul" oluşumunu meydana getirmiştir. Bu okulun farklı anlayışlarını benimseyen temsilcileri de, kendi ekollerini oluşturarak 'Ulusal Okul'larının gelişmesine ve ilerlemesine katkıda bulunmuştur' (Ulucan Weinstein, 2011, s. 1).

\section{Keman Eğitiminde Ekoller}

Günümüzde küreselleşme ve kültürlerarası iletişimin artması ile birlikte bilim, sanat ve eğitimde bir sentez ve birbirlerinden etkilenmesi kaçınılmaz ortak bir kültür oluşmuştur denilebilir. Bu durumda keman eğitimi ekolleri özeline bakılacak olursa, "binlerce müzisyen artık tek bir ekole bağlı olduğu söylenemeyecek şekilde yaylı çalgı çalmakta ve eğitim sürecinde farklı ekollerin temsilcileriyle çalışarak, farklı özelliklerini kendi beğenisiyle birleştirerek kullanabilmektedir" (Göküstün, 2012, s. 69). Bu süreci daha iyi algılayabilmek ve günümüzdeki oluşumları daha başarılı sentezleyebilmek açısından 17. yy.'dan günümüze var olmuş keman ekollerini gözden geçirmekte fayda vardır. Burada sırası ile İtalyan, Fransız, Alman, Fransız-Belçika ve Rus keman ekolleri araştırılmış, bu okulların oluşmasına katkı sağlayan isimlerden kısaca bahsedilmiştir.

\section{İtalyan Keman Ekolü}

17. yy. başlarında İtalya'da Biagio Marini (1587-1663) tardo, presto, forte, piano gibi ifade terimleri ve çeşitli triller ile keman çalma tekniği ve keman icrasının gelişiminde daha yüksek bir ustalık mertebesine ulaşmasında önemli bir yer tutmaktadır. Keman için yazmış olduğu Capricio Stravagante (1627) eserinde Farina, col legno ve pizzicato tekniklerini kullanmıştır. Bu dönemde Mario Ucellini (1603-1680), Giovanni Legrenzi (1626-1690), Tomaso Antonio Vitali (1663-1745), kemanın ilk kez solo olarak kullanıldığı concerto grossolar yazan Giuseppe Torelli, tüm kemancıların atası kabul edilen Arcangelo Corelli (1653-1713), Corelli’nin öğrencileri Francesco Geminiani, Pietro Locatelli ve Giovanni Battista Somis ve J.B.Anet; ikiyüz otuz keman eseri yazan ve kemanın yerini yücelten besteci Antonio Vivaldi (1678-1741), İtalyan keman çalma sanatının Fransa'ya aktarılması yönünden önemli bir geçis noktası olarak kabul edilen Corelli'nin ve Vivaldi'nin öğrencisi olmuş Antonio Vivaldi (1678-1741), Francesco Maria Veracini (1690-1768), Padua'daki Ulusların Okulu olarak adlandırılan School of Nations'in kurucusu, aynı zamanda 1754 yılında yayınlanan Müzik Bilgisi kitabının yazarı Guiseppe Tartini (1692-1770), Pietro Locatelli (1695-1764), 
arco mango olarak adlandırılan grand bow (genis-büyük yay) kullanımını ve zengin ve dolgun ses üretimini öğrencilerine aktaran Gaetano Pugnani (1731-1798), Pietro Nardini (1722-1793), Francesco Geminiani (1687-1762) İtalyan Keman Okulu'nun temsilcileri olmuşlardır (Ulucan Weinstein, 2011, ss. 8-20).

18. yy'ın başında, Arcangelo Corelli (1653 - 1713), Giuseppe Torelli (1658 - 1709), Antonio Vivaldi (c. 1675 - 1741), Giovanni Battista Somis (1676 - 1763), Francesco Geminiani (1680 - 1762), Francesco Maria Veracini (1690 - 1750), Pietro Locatelli (1693 - 1764) ve Giuseppe Tartini (1692 - 1770) gibi kemanc1 - besteciler tarafindan temsil edilen İtalya, müzik alanında diğer ülkelere göre daha baskındır. Sonat ve konçerto formunu geliştirmeleri, cantabile melodiler, parlak figürizasyon, ifade ve "aklı etkileyerek tutkulara yön vermek" üzere kullanılan dramatik efektleri içeren icra ve kompozisyon stilleri, müziğin diğer ülkelerdeki gidişatını da oldukça etkilemiştir. Bu dönemde, özellikle İngiltere başta olmak üzere pek çok ülkede müzikle ilgili önemli görevlerde İtalyanlar bulunmaktadır (Stowell, Aktaran: Öztürk: 3).

\section{Fransiz, Keman Ekolï}

Araştırma konularımızdan biri de Fransız Keman Okulu'dur. Fransız Keman Okulu tüm kemancıların bildiği, tanıdığı büyük kemancılar tarafından kurulmuş ve döneminin en iyi öğrencilerini yetiştirmiştir.

Bunlar içerisinde; 1704 yılında yayınlanan Sonatas and other Pieces isimli albümü yayınlanan, sıcak ve duygulu İtalyan sonat yazım stilini akılcı ve kibar Fransız sonatı stiline dönüstüren besteciler arasında yer alan François Duval, Jean-Fery Rebel, İtalyan keman çalma sanatını Fransa'ya taşıyan önemli isim Jean Baptiste Anet, Jean Marie Leclair (1697-1764) ve Louis-Gabriel Guillemain (1705-1770) ile Fransiz keman okulunun temelleri atılmaya başlanmıştır. Jean Cassanea de Mondoville (1711-1772), Vivaldi ve Corelli'den etkilenen Jean Marie Leclair ve öğrencisi Fransız konçerto formunun ilk örneklerini veren Gavinies (1728-1800) 24 Matinees adlı etütlerinde teknik zorluk açısından Paganini'ye yakın bir içerik sergilemiştir (Ulucan Weinstein, 2011, ss. 27-29). İtalyan asıllı Giovanni Battista Viotti Fransız Keman Okulu'nun kurucusu olarak kabul edilir. 29 keman konçertosu ve keman düolarıyla, ayrıca yaylı sazlar kuartetleri ile keman edebiyatına katkılarda bulunmuş önemli öğrenciler yetiştirmiştir (Karakaya, 2015, s. 5).

Fransız Keman Okulu'nun yetiştirdiği öğrenciler arasında Pierre Rode (24 Capriccios, 13 keman konçertosu), aynı zamanda çok iyi bir keman eğitimcisi olan Rodolphe Kruetzer ("42 Etudes ou Caprices", baleleri ve operaları da vardır), ve Pierre Baillot ("L'art du Violon"), sayılabilir. Fransız Okulu'nda önemi yadsınamaz eserleriyle yer alan bu kemancılar keman edebiyatında büyük önem arz etmektedirler (Karakaya, 2015, ss. 13-17).

\section{Alman Keman Ekolii}

Almanya 18. yy'da, Heinrich von Biber (1644 - 1704), J.J.Walther (1650 - 1717), ve J.J.Walther (1650 - 1717)gibi erken dönem temsilcileriyle başlar ve L. Mozart'nn Versuch ...adlı eseriyle zirveye ulaşır. Bu ekolün önemli isimlerinden biri de şüphesiz ki Ludwig Spohr'dur (1784-1859). Rode'dan büyük ölçüde etkilenen Spohr'un yazdığ 1 eserler Rode, Kruetzer ve Viotti’nin eserlerini gölgede bırakır niteliktedir. Yazdı̆̆ 1 Violinschule, konçertoları, oda müziği eserleri ve düetleri Fransız Keman Ekolün'ün karakteristiklerini yansıtır. Belki de kemanın gelişim süreci içerisinde en büyük katkılardan birini yapmış, 1820 yılında çeneliği bulmuştur. Spohr'un yanısıra onun öğrencilerinden Leipzig Keman Çalma Okulu'nun babası sayılan Ferdinand David, Joseph Joachim ve Andreas Moser sayılabilir (Öztürk, 2012, ss. 6-9). Ferdinand David Gewandhous Leipzig Orkestrası'nın liderliğinin yanısıra, 1843 yılından itibaren Leipzig Konservatuarı’nda keman profesörü olarak görev yapmıştır (Ulucan Weinstein, 2011, s. 67).

\section{Fransız - Belçika Keman Ekolï}

Belçika Keman Okulu'nun temeli; Viotti ilkeleri ile Baillot, Rode ve Kreutzer tarafından gelistirilen Fransız Keman Okulu yapısı geleneği ile Paganini'nin çarpıcı ihtişamının da etkileri görülen bir icracı ve besteci olan Charles Auguste de Beriot (1802-1870) tarafından 1840 yılları dolaylarında atılmıştır (Ulucan Weinstein, 2011, s. 77). Paganini'den ilham aldığını söyleyen ve Schumann'ın, "etrafında topladığı hayranlarının "sihirli çemberinden" bahsettiği Henry Vieuxtemps de Fransız -Belçika Ekolünün önemli kemancıları arasında yerini alır. Bu ekolün diğer iki önemli ismi ise Pablo de Sarasate (1845 - 1908) ve Eugene Ysaye (1858 - 1931)'dir (Öztürk, 2012, s. 10).

"Keman öğreniminde ilk yay hareketini en kalın tel olan sol telinde başlatan Beriot, sol el pozisyonunu yine aynı tele konumlandırılan la -si - do - re notaları üzerine konumlandırılan 1-2-3-4 parmakları ile göstermektedir. Buna göre Alman Okulu ve Fransız Okulunun aksine sol el başparmağı işaret parmağı ile karş1lıklı değil, işaret ve orta parmak karşısında yer almaktadır” (Ulucan Weinstein, 2011, s. 79). 


\section{Rus Keman Ekolü}

İtalya, Almanya ve Fransa gibi ülkelerin aksine Rusya'da, 19. yy'ın sonlarına, hatta 20. yy'a dek, 'ulusal' bir ekolün varlığından söz edilemez. Yine de bu dönemde iki büyük keman sanatçısından söz edilebilir ki bunlar Ivan Khandoshkin (1747- 1804) ve Nikolai Afanasiev (1821 - 1898)'dir. Rus keman okulu'nu oluşturan Wieniawsky, Auer, Stolyarsky, Galamian, Yampolsky ve Yankelevich gibi önemli isimler de say1labilir.

\section{Türkiye'de Keman Eğitiminde Kullanılan Ekoller}

Türk keman eğitimi hayatına oldukça önemli katkılarda bulunan eğitimcilerin hatırı sayılır bir kısmı Almanya'dan gelmiş müzisyenler; bir kısmı Almanya'da eğitim görmüş hocalar, bir kısmı da Fransa'da eğitim almış kişilerdir. Dolayısıyla ülkemizde ekollerden bahsedilirken doğal olarak eğitim alınan ülkelerin ekolleri, ülkemizdeki keman eğitimini etkilemiştir denilebilir. Türkiye'deki keman eğitiminden söz ederken aşağıda sıralanmış olan keman sanatçıları ve sanatçı keman öğretmenlerini mutlaka anmak gerekir.

Henry Charles Wondra (Vondra Bey, 1868-1905-08) Osman Zeki Üngör (1880-1959) Fransa'da, Basri Bey, Licco Amar (1891-1959) Budapeşte'de başlayıp Berlin, Karl Berger (1894 - 1947) Avusturya, İzzet Nezihi Albayrak (1898-?) Almanya, Seyfettin Asal (1901- 1955) Avusturya'da, Halil Rifat Onayman (1902- 1962) Almanya'da, Ekrem Zeki Ün (1910-1987) Paris’te, Orhan Borar (1910-1983), Necdet Remzi Atak (1911-1972) Almanya'da, Fethi Kopuz (1915- 1996) İngiltere'de, Edip Günay (1931-2010) Almanya'da, Ayla Erduran (1934- ) Fransa'da, Ömer Can (1934) Almanya'da, Suna Kan (1936- ) Fransa'da, Oktay Dalaysel (1938- ) Almanya'da, Saim Akçıl (1940 - ) Almanya'da, Ali Uçan (1941 - ) Almanya'da, Hazar Alapınar (1942 - ) Almanya'da, İsmail Aşan (1951 - ) Fransa'da, Tunç Ünver (1953 - ) Fransa'da, Cihat Aşkın (1963- ) ise İngiltere'de eğitim almışlardır (Ulucan Weinstein, 2011, ss. 159-198).

Türkiye'de kullanılan keman ekollerine değinirken çok önemli bir yere sahip olan Prof. Dr. Cihat Aşkın'ın görüşlerine de yer vermek yerinde olacaktır. Sanatçı, Ayla Erduran ve Suna Kan'dan sonra Türk Keman Okulu'nun üçüncü temsilcisidir. Ancak bu okulun adı Cihat Aşkın ortaya çıkana kadar konulmamıştı. Cihat Aşkın Türk Keman Okulu'nun temsilcisi olarak çok sayıda uluslararası davet almıştır. Ayrıca Türk kemancılarının ve ülkemizdeki keman sanatının tarihinin aydınlatılması, ayrıca keman eserlerinin ortaya çıkarılıp seslendirilmesi konusunda da çalışmaları ve katkıları büyüktür (Doğanay, 2015, s. 82). Türkiye'deki ekollere baktığımızda, özellikle kemancıların yüz yıl içinde katettikleri mesafe oldukça iyi bir mesafe sunar. Osman Zeki Üngör'le başlayıp Suna Kan ve Ayla Erduran'a kadar varan dünya çapında sanatçılarımız bulunmaktadır. Osman Zeki Üngör Ankara'da, oğlu Ekrem Zeki ise İstanbul'da keman öğretmenliği yapmıştır. Ankara ekolünü Alman ve Belçikalı hocalar geliştirirler. Orta kuşak kemancılardan Tunç Ünver ve İsmail Aşan sayılabilir (Doğanay, 2015, s. 90).

\section{Türk Keman Okuluna İlişkin Uzman Görüşleri}

Türkiye'de Keman eğitiminde kullanılagelmekte olan keman ekolleri üzerine yaptığımız bu çalışmada, konu ile ilgili Müzik Eğitimi Anabilim Dallarında görev yapmakta olan 3 uzman keman eğitimcisi ve devlet konservatuvarlarında görev yapan 2 uzman sanatçı keman eğitimcisi ile görüşme yapılmıştır. Uzman görüşleri doğrultusunda ülkemizdeki keman eğitiminden bahsedilmiş ve Türkiye'ye özgü bir keman ekolü olup olmadığı konusundaki görüşleri alınmıştır.

\section{Keman eğitimi aldığını okul/okullar hangileridir. Bu okul/okullarda keman eğitiminde hangi ekoller kullanulyyordu?}

Çalışmaya katılan uzmanlarımızın mezun oldukları okullar sırası ile:

Gazi Eğitim Enstitüsü, Anadolu Üniversitesi Devlet Konservatuvarı, Moskova Çaykovski Devlet Konservatuvarı, Gazi Üniversitesi, Abant İzzet Baysal Üniversitesi ve Dokuz Eylül Üniversitesi Devlet Konservatuvarı.

Çalışmaya katılan uzmanlarımızın eğitim aldıkları ekoller sırasıyla:

-Gazi Üniversitesi, Abant İzzet Baysal Üniversitesi, Bu okullarda eğitimcilerin yetiştikleri ekol ve tecrübeleri doğrultusunda, Alman, Fransız-Belçika ve Rus ekolleri kullanılıyordu.

-Gazi Eğitim Enstitüsü. Alman, Fransız ve İtalyan ekolleri

-Hocam Almanya'da eğitim gördüğü için aldığım eğitimde Alman Ekolü kullanılıyordu

-Sadece DEÜ Devlet Konservatuvarı'nda okudum. Rus ve Alman Ekolü ağırlıkta idi. 
Tablo 1. Uzmanların eğitim almış oldukları ekoller

\begin{tabular}{cl}
\hline Ekoller & $\mathrm{n}$ \\
\hline Alman & 4 \\
Fransız & 1 \\
İtalyan & 1 \\
Rus & 3 \\
Fransız-Belçika & 1 \\
\hline
\end{tabular}

Tablo 1'de görüldügü gibi uzmanların 4'ü Alman, 2'si Fransız ve 1'er tanesi de Fransız, Fransız Belçika ve İtalyan ekolüne bağlı kalarak eğitim almışlardır.

Siz derslerinizde öğrencilerinizi yetişstirirken hangi ekole bağlı kalarak ĕ̆itim veriyorsunuz?

-İtalyan ve Fransız ekolleri olduğunu söyleyebilirim.

-Ekollerin kesin çizgilerle ayrılmadığını düşünsem de eğitimim itibariyle öğrencilerime de Rus Ekolü’nü aktarıyorum. -Alman ve Fransız-Belçika ekollerini kullanmaktayım.

-Usta çırak ilişkisinden dolayı Alman Ekolüne bağlı kaldığım söylenebilir.

-Herhangi bir ekole bağlı çalışmıyorum. Bütün ekollerde öğrencinin fiziksel yapısına uygun en doğal tutuş un olması gerektiğine inanıyorum. I. Galamian'ın eğitim yöntemi benim düşüncelerimi destekler niteliktedir.

Tablo 2. Eğitimde kullandıkları ekoller

\begin{tabular}{cl}
\hline Ekoller & $\mathrm{n}$ \\
\hline Alman & 2 \\
Fransız & 1 \\
İtalyan & 1 \\
Rus & 2 \\
Fransı-Belçika & 1 \\
\hline
\end{tabular}

Tablo 2’de görüldüğü gibi, uzmanlarımız eğitim verirken Alman ve Rus ekollerini ağırlıklı olarak kullanmaktadır.

\section{Türkiye'de en çok kullanılan keman ekolü sizin gözlemlerinize göre hangisi/hangileridir?}

-Fransiz, Alman ve Rus

-Önceleri Fransız ekolü, daha sonra Macar, Alman ve Rus müzisyenlerin Türkiye’ye gelmesiyle bu ekoller de ülkemizde kullanılmıştır. Dolayısıyla ülkemizde Alman, Macar ve Rus ekollerinin ağırlıklı olarak kullanıldığını söyleyebilirim.

-Ülkemizde de daha çok Alman ekolünün, son 10-15 y1llık süreçte de Rus ekolünün daha çok kullanıldığını gözlemlemekteyim.

-Sanırım okullardaki hocaların eğitim almış oldukları ülkelere göre farklılaşıyor. Fakat Rus Ekolü ve Alman Ekolü en çok kullanılanlar.

-Yurt dışından gelen hocalara göre bir ara Rus ağıllıklı bir ara Alman ağırlıklı olabiliyor.

Tablo 3. Türkiye'de kullanılan keman ekolleri

\begin{tabular}{cc}
\hline Ekoller & $\mathrm{n}$ \\
\hline Alman & 3 \\
Fransız & 1 \\
İtalyan & 1 \\
Rus & 4 \\
Macar & 1 \\
Fransız-Belçika & - \\
\hline
\end{tabular}

Tablo 3'te görüldüğü gibi ülkemizde Rus ve Alman ekolleri ağırlıklı olarak kullanılmaktadır. 
-Türk keman ekolünün oluşması için tamamen Türk müziğinden yola çıkılması gerektiği dile getirilmiştir. Türk müzikçilerinin makamlar ve usuller hakkında henüz birleşemediklerini, bu nedenle Türk müziğinden yola çıkılarak keman eğitimi için bir sistematiğin olabilmesinin zor bir süreç olduğu saptamasında bulunulmuştur. Ancak Türk müziği çıkışlı arayış çalışmalarının mevcut olması ile birlikte, henüz Türk keman ekolü oluşmuştur denemeyeceği, zamana ihtiyacın olduğu vurgulanmıştır.

-Artık dünyada böyle kesin çizgilerin bulunmadığını dile getiren eğitimci, teknik ve müzikal özellikleri belirtebileceğimiz net bir Türk Keman Ekolü’nden bahsedilemeyeceği gibi Türkiye'de uluslararası standartlarda müzisyen yetiştirilebildiğini dile getirmiştir.

-Bir takım çabalar olsa da ülkemizde bir keman ekolünün henüz oluşmadığı belirtilmektedir.

-Bunlarla birlikte uzmanlarımız keman ekolü oluşturma konusunda başarılı olmadığımızı dile getirmiş, başka bir uzman eğitimci ise bir "Türk Keman Okulu yoktur” gibi keskin bir ifade ile düşüncelerini belirtmiştir.

\section{Sonuç ve Öneriler}

Avrupa'da yüzlerce yılın kültürü ile beslenerek gelen klasik müzik geleneğinin içerisinde yer alan keman müziği, 17. yy'dan itibaren başta İtalya olmak üzere Almanya, Fransa ve Rusya gibi ülkelerde gelişmiştir. Her biri keman konusunda okul geleneğini oluşturabilmiş ve Vivaldi, Beriot, Viotti, Biber gibi keman edebiyatında önemli yer tutan müzisyenleri yetiştirmişlerdir. Bu besteci ve kemancılar, zamanla kemanda elde ettikleri ustalıkla kendi ülkelerinin ekollerini oluşturmuşlardır.

Ülkemizdeki müzik okullarında görüşme yapılan keman eğitimcilerinin ağırlıklı olarak Alman, Rus, Fransız, İtalyan ve Fransız - Belçika ekollerine bağlı kaldıkları belirlenmiştir.

Yapılan araştırmada Türkiye'de en çok kullanılan ekollerin Rus, Alman, Fransız ve İtalyan ekolleri olduğu, ayrıca günümüzde okullarda kullanılan ekollerin keskin çizgilerle ayrılamayacă̆ı saptanmıştır.

Prof. Dr. Cihat Aşkın'ın çok önemli hatırı sayılır çalışmalarının olmasının yanında genel resme daha yakından bakıldığında, ülkemizde bir keman eğitimi ekolünün henüz oluşmadığı sonucuna ulaşılmıştır. Türkiye'de, bu konuda Avrupa ülkelerine göre çok yeni bir geçmişimiz olması nedeniyle yakın gelecekte bir keman ekolü oluşumunun da zor olduğu uzman görüşleri doğrultusunda belirlenmiştir. Ayrıca Türk Keman Ekolü’nün oluşabilmesi için Türk müziğinden yola çıkılması gerektiği belirlenmiştir.

İçinde kendi kültürünün yapıtaşlarını barındıran bir eğitim sistemi, dolayısıyla kendi müzik ögelerimize bağlı kalınarak oluşturulmuş bir keman eğitimi Türk Keman Ekolü’nün sağlıklı bir şekilde oluşturulmasını sağlayacaktır.

Türk Keman Ekolü'nün oluşabilmesinin önemli koşullarından birisi de, öğretim teknik ve materyallerin geliştirilmesine bağlıdır. Bu materyallerin geliştirilmesinde temelde Türk müziğinden yola çıkılmalı ve buna yönelik çalışmalar yapılmalıdır. Bir ekolün oluşabilmesi için başlangıç düzeyinden en üst düzeylere kadar yazılan eser ve etütlerin bulunduğu bir külliyata ihtiyaç vardır. Bunun oluşabilmesi için uzun zamana ihtiyaç olmakla birlikte, her zaman yapılan çalışmaların üzerine konularak ilerleme sağlanması gerektiği düşünülmektedir. 


\section{Extended Summary}

\section{Introduction}

Mankind has always resorted to various ways to express himself since he has existed and first achieved this with his own voice and body, as might be expected. Man, who discovered his own voice, carried out the action of speaking in time, to communicate with others. Man, having used his own voice and body, identified different sounds using different materials in nature and learned to transform them into music. In addition, in order to be able to express himself and maintain communication with others, by also painting cave walls, he presented his first works of art in a visual and auditory context.

The first thought and culture production appeared when human beings began to make tools. The Paleolithic Age, which consisted of lower, middle and upper Paleolithic periods, qualifies as a preliminary period for the Neolithic Period. The tools made in the upper Paleolithic period were generally for hunting purposes. In addition to the tools he used to protect himself or hunt, man made musical instruments as well. Based on the theories of Curt Sachs, it can be seen that the instruments were made simply at first to more complicated later, and created in this way. Besides, Sachs stated that percussion instruments were produced first since the basis of music is rhythm, which provided a flow of time with tempo, beat and meters (Sachs, 2006, ss. 25-26, in Dönmez, 2015, pp. 59-60).

The emergence of the violin in its present form, which is the subject matter of the present research, coincides with the final period of the Renaissance. It is also mentioned in the Bible and old psalms that there were stringed instruments played with fingers and it is known that the bow appeared a long time later. With the studies he conducted based on the paintings and manuscripts of the Byzantium period and from Islamic history in the 10th and 11th centuries, Bachmann found out that the history of the bow dated back to those periods. The bow was spread to Europe from the east through conquests. The use of the bow, which had been reserved by the Arabian and Byzantines till the end of the 10th century, was spread to Europe from Spain in the 11th century (Nelson, 2003, p. 1-2).

In the research studies carried out in the 20th century, it was emphasized that the evolution of the violin occurred in the form of Rebec-Fidel-Lira da braccio-violin (Kerimov, 2015, p. 248).

It is also known that the origin of the Rebec instrument is based upon the Arabic instrument Rebap. In his work called Mukaddimah (Introduction), Ibn Khaldun described the Rebap instrument which is known, thanks to the written sources, to date back to the 9th century and he mentioned a type of Rebab that is put on the lap and played with a bow. Before this, it is assumed that the Rebab was spread during the crusades in the 11th century, from North Africa to Europe.

Problem: What are the schools of violin education utilized around the world and what are the expert opinions on the schools in Turkey and the Turkish Violin School?

1. What are the violin education schools that are presently being utilized around the world?

2. What are the schools applied in violin education in Turkey?

3. What are the expert opinions on the Turkish violin school?

\section{Method}

In this study, which is a descriptive study, information regarding the research topic was gathered through a literature review in the first step. On the other hand, in the qualitative part of the study, opinions and suggestions were provided via interviews with experienced violin artist educators and expert violin educators.

\section{Sampling}

The sample of the study in the qualitative part comprised of a total of five violin educators consisting of three faculty members in the department of music education and two lecturers in a state conservatory. The institutions where the participants work are the Department of Music Education at Gazi University, Nigde University, and Mehmet Akif Ersoy University and the State Conservatories of Dokuz Eylul University and Anadolu University.

\section{Schools in Violin Education}

\section{Findings and Interpretations}

When you look at Italian violin art schools, it is highly possible to encounter some really well known composers like Ucellini, Vitali, Torelli, Corelli, Vivaldi, Veracini. These composers have a great role in the evolution of the violin in 
Italy. In the Italian violin art school, small and large scale works were provided for violin and stringed instruments, which contributed to the development of this instrument in its technical and physical aspects.

As for the French violin school, it is seen that study books which are of critical importance for violin literature have been written. Among these, Leclair, who provides works in sonata form, and Rode, Kruetzer and Baillot, who stand out with their studies, can be given as examples.

When it comes to the German violin school, it is seen that, while the prominent figure is Spohr, David, Moser and Joachim are among the leading violinists of this school.

In the French-Belgian violin school, on the other hand, Beriot, Vieuxtemps and Sarasate and Ysaye are considered as outstanding composers.

In the Russian school, Khandoshkin, Afanasiev, Wieniawski, Auer, Stolyarsky, Galamian, Yampolsky and Yankelevich can be given as some of the important names.

\section{Schools Utilized in Violin Education in Turkey}

It was revealed that experts who were interviewed received their education mainly from German and Russian schools as well as French, Italian and French-Belgian schools. Schools applied in education, on the other hand, were identified to be predominately German and Russian again. According to their observations in Turkey, the most frequently applied schools are Russian and German schools; they also stated that they observed the existence of some other schools. The experts answered the question whether a violin school has emerged in Turkey by stating that there has been no violin school yet. It was asserted that in order to create a Turkish violin school, it should be completely established on the basis of Turkish music. They came to the conclusion that Turkish musicians haven't agreed on modes and procedures yet and so the process to create a system in violin education based on Turkish music would be a difficult one. However, it is emphasized that despite the efforts to reach a Turkish-music-based approach, it cannot be said yet that a Turkish violin school has been created; some time is needed for this. On the other hand, the experts stated that there are no such sharp differentiations in the world any more, and argued that it is not possible to mention a clear-cut Turkish violin school whose technical and musical qualities can be identified, and that musicians can be educated with international standards in Turkey. Moreover, our experts claimed that we are not that successful about creating a violin school and another expert trainer, on the other hand, said "There is no Turkish Violin school" with a clear and sharp expression.

\section{Conclusion and Discussion}

Violin music that existed in the classical music tradition with its rich cultural accumulation in Europe for hundreds of years evolved starting from the 17th century in countries such as Italy (in the first place), Germany, France and Russia. Each of them has been able to develop their own violin school traditions and raised the most prominent figures in violin literature such as Vivaldi, Beriot, Viotti, and Biber. These composers and violinists, with the specialization they had in the violin, created the schools of their own countries over time. It has been determined that the violin educators interviewed in the music schools in our country are mostly under the influence of the German, Russian, French, Italian, and French - Belgian schools.

Despite the fact that Professor Dr. Cihat Aşkin produced remarkable studies, when we look closer at the general picture, it was concluded that a violin education school has not been created yet in our country. In Turkey, it was also revealed that as we have a more recent history compared to European countries regarding this issue, the emergence of a violin school in the near future seems difficult. Moreover, it is stated that Turkish music must be the basis in order for a Turkish Violin School to be formed. An education system that contains the essence of its own culture, and therefore a violin education that is built on the basis of our own musical pieces, will ensure the healthy formation of the Turkish Violin School.

One of the important conditions for the formation of the Turkish Violin School is the development of teaching techniques and materials. In the development of these materials, Turkish music should be the basis and studies regarding this issue should be conducted. In order for a school to form, there is a need for a collection of works and 
Akın-Şişman

studies written from the beginner level to the highest level. It is thought that in order to reach this, it will require a long time and the development must be sustained through an accumulation of studies. 


\section{Kaynakça / References}

Büyüköztürk, Ş., Çakmak, K. E., Akgün, Ö. E., Karadeniz, Ş., Demirel, F., (2016). Bilimsel Araştırma Yöntemleri. Ankara: Pegem Akademi

Doğanay, H. (2015). Cihat Aşkın artık melekleri hissetme vaktidir. İstanbul: Pan Yayınc1lık.

Erdal, A. (2010). XVIII. yüzyll ve erken XIX. yüzyll müziğinin keman tekniği ve yorumculuğuna getirdiği yenilikler , (Yayınlanmamış Sanatta Yeterlilik Tezi). İstanbul Üniversitesi Sosyal Bilimler Enstitüsü Yaylı Çalgılar Sanat Dalı Keman Programı, İstanbul.

Göküstün, M. (2012), Galamian yöntemi’nin keman çalma performansı üzerindeki etkisi, İzmir: Dokuz Eylül Üniversitesi Güzel Sanatlar Enstitüsü Müzik Anasanat Dalı, Yayınlanmamış Sanatta Yeterlik Tezi.

Hornbostel, E.M., \& Sachs, C. (1961). Classification of musical instruments, The Galpin Society Journal, 14 (Mar., 1961), 3-29. (Çev: Anthony Baines and Klaus P. Wachsmann), (Özgün çalışma: 1914).

Karakaya, E. (2015). G. B. Viotti, Fransız keman okulundaki yeri ve 23 nolu keman konçertosunun analizi (Yayınlanmamış Yüksek Lisans Tezi). Cumhuriyet Üniversitesi Sosyal Bilimler Enstitüsü Müzik Anabilim Dalı, Sivas.

Kerimov, R. (2015). Kemanın oluşum süreci bağlamında eski yaylı çalgıların etkisi üzerine genel bir değerlendirme. The Journal of Academic Social Science Studies International Journal of Social Science, 40, 247-258. Doi number: http://dx.doi.org/10.9761/JASSS3167.

Miller, H. M. (1973). History of music. New York: Barnes Noble Books.

Mustan Dönmez, B. (2015). Müziğin kökeni üzerine. İstanbul: Bağlam Yayınları.

Nelson, S. (2003). The violin and viola history, structure, techniques. New York: Dover Publications Inc.

Öztürk, Ö.D. (2012). 20. Yüzyll Rus keman ekolünde pedagojik yaklaşımlar ve sağ el teknikleri ile ilgili uygulamalar. (Müzik Anasanat Dalı Yaylı Çalgılar Sanat Dalı Yayınlanmamış Sanatta Yeterlik Tezi). Trakya Üniversitesi Sosyal Bilimler Enstitüsü, Edirne.

Sachs, C. (2006). The history of musical instruments. New York: Dover Publications, Inc.

Sevsay, E. (2013). The cambridge guide to orchestration. New York: Cambridge University Press.

Stowell, R. (2004). The early violin and viola a practical guide. Cambridge: Cambridge University Press.

Türkçe Sözlük (2005). Şehir: Türk Dil Kurumu.

Ulucan Weinstein, S. (2011). Türk keman okulu'nun oluşumu (Yayınlanmamış Sanatta Yeterlilik Tezi). İstanbul Üniversitesi Sosyal Bilimler Enstitüsü Yaylı Çalgılar Sanat Dalı Keman Programı, İstanbul.

Zaslaw, N. (1990). The italian violin school in the 17th century. Early Music, 18(4), 515-518. 